\title{
A Imagem Corporativa e seus Reflexos: um Estudo de Imagem da Polícia Militar de Santa Catarina na Perspectiva de Moradores da Grande Florianópolis
}

\section{The Corporate Image and its Reflexes: an Image Research of the Military Police of Santa Catarina in the Perspective of Residents of Florianópolis and Nearby}

\author{
Aline Regina Santos \\ Universidade do Estado de Santa Catarina - UDESC - SC - Brasil \\ aline.santos@udesc.br \\ Orcid-0000-0001-9116-9247 \\ Fabíola Gostek Pessôa \\ Universidade do Estado de Santa Catarina - UDESC - SC - Brasil \\ fabiolagpessoa@gmail.com \\ Orcid - 0000-0001-7121-0687 \\ Ana Paula Grillo Rodrigues \\ Universidade do Estado de Santa Catarina - UDESC - SC - Brasil \\ agrillorodrigues@gmail.com \\ Orcid - 0000-0001-6617-1679
}

Submetido em 02/05/2018; Aprovado em 26/09/2018

\begin{abstract}
Resumo
A imagem corporativa é tratada na literatura acadêmica como aquilo que o público-alvo imagina ao se fazer referência a determinada organização. Seu processo de formação, portanto, tem natureza complexa e suas implicações podem levar à confiança ou descrença na organização. Considerando a relevância do tema, o presente artigo tem como objetivo identificar a imagem percebida da Polícia Militar de Santa Catarina (PMSC) por moradores da Grande Florianópolis, Santa Catarina. Para tanto, foi aplicada pesquisa survey presencial com 367 pessoas que transitaram na região central de Florianópolis, em setembro de 2017. 0 instrumento foi desenvolvido em formato híbrido, sendo os dados qualitativos analisados visando categorização das respostas em imagem positiva, negativa e neutra. A estatística descritiva e teste qui-quadrado foram aplicados aos dados quantitativos, visando maior compreensão do fenômeno. Entre os principais resultados, destaca-se que a maioria dos respondentes possui uma imagem neutra frente à PMSC, sendo o termo "segurança" a associação preponderante. A relação entre imagem e orientação política, bem como entre imagem e avaliação do atendimento sugerem elementos que influenciam diretamente a percepção, corroborando pontos levantados na teoria. A pesquisa traz implicações gerenciais no tocante à comunicação corporativa e propõe algumas considerações sobre imagem corporativa em organizações públicas.
\end{abstract}

Palavras-chave: imagem corporativa, pesquisa de imagem, Polícia Militar de Santa Catarina

\section{Abstract}

The corporate image is treated in the academic literature as what the target audience imagines when referring to an organization. Its formation process, therefore, has a complex nature, and its implications can lead to trust or disbelief in the organization. Considering the relevance of the theme, this article aims to identify the perceived image of the Military Police of Santa Catarina (PMSC) by residents of Metropolitan Florianópolis, Santa Catarina. Therefore, a face-to-face survey was conducted with 367 citizens who transited in the central region of Florianópolis, in September 2017. The questionnaire was developed in a hybrid format. The qualitative data were analyzed aiming to categorize the responses into positive, negative and neutral images. Descriptive statistics and chi-square test were applied in the quantitative data, looking for a better understanding of the phenomenon. Among the main results, it is highlighted that most of the respondents have a neutral image of the PMSC. Besides, the term "security" was the predominant association. The relationship between image and political orientation, as well as image and personal contact suggest elements that directly influence perception, corroborating points 
raised in theory. The research has management implications regarding corporate communication and proposes some considerations about corporate image in public organizations.

Keywords: corporate image, image research, Military Police of Santa Catarina

\section{Introdução}

Elemento essencial da gestão institucional, a imagem corporativa reflete as associações do público a uma determinada marca, produto ou serviço, tendo impacto direto nas estratégias de comunicação da organização (Schuler \& Toni, 2015). Uma vez que a imagem se encontra presente na mente do público (Gray e Balmer, 1998), a realização de pesquisa de imagem junto ao grupo de interesse constitui-se como etapa necessária a toda organização que deseja ter uma boa reputação (Schuler e Toni, 2015).

As pesquisas de imagem são comumente ancoradas no campo de marketing, vinculadas à gestão da marca e ao marketing institucional (Kotler e Keller, 2012, Yanaze e Mihailidis, 2013), embora também seja possível encontrar a temática associada ao campo da comunicação organizacional e relações públicas (Kunsch, 2002). São estudos de natureza predominantemente quantitativa, podendo ser direcionados tanto ao público interno quanto ao público externo à organização (Schuler e Toni, 2015).

Embora reconhecidos como ferramentas gerenciais (Schuler e Toni, 2015), com aplicabilidade mais empírica do que voltada ao conhecimento científico, os estudos de imagem, especificamente aplicados ao setor público, têm despontado no ambiente acadêmico nos últimos anos. A produção nacional mais recente, identificada durante a elaboração deste artigo, trata de pesquisa de imagem aplicada às ouvidorias públicas, realizada com moradores de Florianópolis/SC (Santos, Costa, Burger e Borja, 2017). Similar, Souza (2016) buscou identificar a imagem percebida do Tribunal de Contas do Paraná entre os moradores de Curitiba. São estudos que trazem em comum a mesma forma de detectar a imagem, mediante a realização inicial da pergunta aberta: "O que lhe vem à mente quando se fala em (nome da organização)"? ou "Em sua opinião, o que é (nome/tipo de organização)"? A análise dos dados é combinada a variáveis demográficas e atitudinais, levando a conclusões a respeito da imagem percebida, bem como aspectos gerenciais relacionados à comunicação do órgão público com a população.

Dos órgãos públicos objetos de análise em pesquisas de imagem, a polícia talvez seja o de maior interesse acadêmico, tanto nacional, quanto internacionalmente - embora o quantitativo de publicações que envolvam estudos de imagem aplicados junto à população ainda seja tímido: apenas oito ao total, no período que compreende de 1992 a 2017. Nos artigos encontrados para fins deste estudo, observouse uma preocupação em identificar possíveis relações entre variáveis demográficas e atitudinais com a imagem percebida da polícia (Cao, 1998; Mello, Toigo e França, 2004, Silva e Beato, 2013), sendo comumente a imagem associada à variável segurança (Cao, 1998; Silva e Beato, 2013) ou satisfação com o serviço prestado (Santos Júnir e Guerini, 2007; Zouain, 2008). Entretanto, a imagem identificada a partir de pergunta aberta, embora recomendada para pesquisas de imagem (Schuler e Toni, 2015; Kunsch, 2002), não foi identificada em nenhum dos trabalhos analisados.

Em que pese a contribuição das publicações mencionadas, observa-se uma lacuna metodológica no tocante aos estudos de imagem aplicados à polícia, motivando a realização da presente pesquisa. Considerando o exposto, este trabalho tem como objetivo propor uma pesquisa de imagem à polícia militar, mediante a utilização combinada de questão aberta sobre a imagem e mensuração de variáveis demográficas, atitudinais e avaliativas em relação à polícia.

A instituição escolhida para a realização de um estudo de imagem foi a Polícia Militar de Santa Catarina (PMSC), uma organização estatal de direito público, pertencente à administração direta do governo estadual, prestando serviços na área de segurança pública, dentro do território catarinense. Importante destacar que outros órgãos públicos também possuem como área de competência a segurança, entre os quais a Polícia Federal, a Polícia Civil, o Corpo de Bombeiros, as Forças Armadas, a Guarda Municipal. Tal situação pode levar a uma dificuldade do público externo na correta associação das competências de cada órgão e à confusão entre a imagem de um e de outro, o que reforça a relevância da aplicação de questão aberta própria aos estudos de imagem.

\section{Referencial Teórico}

\subsection{Imagem Corporativa}

A imagem corporativa é um assunto discutido no ambiente acadêmico desde a década de 1950 e 
que possui variados conceitos de acordo com sua linha temporal. É presente em organizações de todos os âmbitos e setores, de todos os tamanhos e localidades.

A imagem corporativa é um rótulo de uma empresa mantido pelo público, baseado em significados funcionais (qualidade, serviço, preço) e significados emotivos. Em adição, por trás de uma associação entre uma instituição e uma imagem superficial, como, por exemplo, uma companhia aérea associada à ação de se voar aviões, existem ideias vagas e generalizadas que são trazidas à mente por aspectos específicos, como a qualidade da comida servida em voo ou a decoração interior dos aviões. São dessas vagas ideias, desse conjunto de várias associações e significados, que a imagem se refere (Martineau, 1958).

Imagem corporativa também pode ser considerada como uma imagem mental a respeito de uma organização. Imagens corporativas são profundamente multidimensionais e por isso raramente haverá um fator que contemple totalmente a "personalidade" da organização. É muito improvável que todos os grupos com quais a organização interage terão a mesma imagem sobre ela ao mesmo tempo (Dowling, 1986). Tal abordagem fundamenta-se nos preceitos da psicologia social, em específico na Teoria das Representações Sociais de Serge Moscovici, a qual sustenta a ideia de que as imagens e crenças são construções históricas e sociais, representando a imagem de um coletivo (Moscovici, 2015).

Entretanto, Kunsch (2003, p. 170) lembra da perspectiva individual ao afirmar que a imagem "tem a ver com o imaginário das pessoas, com as percepções. É uma visão intangível, abstrata das coisas, uma visão subjetiva de determinada realidade". Nesta perspectiva, a imagem é formada a partir da experiência do indivíduo com a organização, as emoções, vivências e a intensidade do contato, gerando distintas associações que podem permanecer na memória, conforme a força de tais associações (Schuler \& Toni, 2015).

Apesar de complexo, o gerenciamento da imagem é tido como relevante às organizações por variados motivos. Entre eles, cita-se a influência que uma boa imagem corporativa tem no comportamento do consumidor, podendo levar a "advocacy", ou seja, situação que ocorre quando o público-alvo atua em "defesa" da organização (Tran, Nguyen, Melewar, Bodoh, 2015). Para tanto, o monitoramento da imagem e o uso das informações obtidas nas estratégias de comunicação corporativa são ações essenciais para o alcance de uma reputação positiva e da postura de "advocacy" do públicoalvo (Gray \& Balmer, 1998; Tran et al., 2015).

\subsection{Pesquisa de Imagem em Instituições Públicas}

A pesquisa de imagem é uma ferramenta tradicionalmente conhecida como pertencente ao âmbito do marketing, feita para se coletar a percepção e associações do público a uma determinada organização. Esta pesquisa identifica a reputação de uma organização ao verificar se a instituição é bem ou malvista por seus stakeholders. O monitoramento da imagem possibilita o embasamento das estratégias e posicionamento da organização, visando o alcance de seus objetivos (Schuler \& Toni, 2015).

Comumente as pesquisas de imagem são aplicadas a organizações, marcas, produtos ou serviços - os quais podem ser do setor público, privado ou terceiro setor (Schuler e Toni, 2015). Vaz (2003) lembra que a imagem faz parte do "simbólico" de uma organização, das ideias e associações relacionados a um determinado objeto, podendo este objeto assumir diferentes formas. Portanto, a literatura não aponta um tipo específico de pesquisa de imagem para organizações do setor público, embora ressalte os benefícios de sua aplicação, como a possibilidade do órgão público compreender as percepções do cidadão e aprimorar o direcionamento das suas ações de comunicação (Duarte, 2007).

No tocante aos aspectos metodológicos, as pesquisas de imagem normalmente são de abordagem predominantemente quantitativa, com uso de perguntas abertas para mapeamento de associações, embora métodos mistos sejam os mais adequados (Schuler e Toni, 2015). 0 Método de Configuração de Imagem (MCI) proposto por Schuler e Toni (2015), combina as abordagens quali e quantitativas e sugere a realização de três etapas: a Configuração de Conteúdo de Imagem, a Configuração de Agrupamentos e o Relatório de Resultados.

Após a identificação do público-alvo de interesse para organização, aplica-se a "Configuração de Conteúdo", etapa em que ocorre a identificação dos atributos de imagem da organização, marca, produto ou serviço pesquisados, presentes na mente dos entrevistados. Os atributos mencionados são de naturezas diversas, envolvendo aspectos racionais, afetivos, simbólicos, sensoriais, entre outros. Segundo os autores, o indicado é obter essas percepções mediante aplicação de perguntas abertas, iniciando com questão de atributos top of mind, caracterizada pela pergunta "Quando eu digo (TERMO 
INDUTOR), qual a primeira coisa que lhe vem à mente? (Schuler e Toni, 2015, 160). Outras questões abertas podem ser feitas na sequência, tais como "Do que você gosta/não gosta no (TERMO INDUTOR)?" - referente ao atributo emocional; "Qual a utilidade do (TERMO INDUTOR) para você?" - referente ao atributo racional; "Quais sentimentos lhe vêm à mente sobre (TERMO INDUTOR)? - referente ao atributo afetivo. Os autores indicam a análise de conteúdo como procedimento para categorização das dimensões de imagem coletadas na pesquisa, a partir da frequência em que os elementos são mencionados e da ordem como são manifestados nas respostas.

$\mathrm{Na}$ etapa de "Configuração de Agrupamentos" os autores sugerem mensurar o grau de importância dos atributos levantados na fase anterior, bem como identificar a satisfação dos entrevistados com tais atributos. Por fim, indicam o formato de relatório adequado, sugerindo a forma como as informações devem ser transmitidas à organização objeto da pesquisa de imagem.

É interessante observar que Schuler e Toni (2015) não abordam a análise combinada da imagem às variáveis demográficas, sociais ou atitudinais, como observados nos estudos de Santos, Costa, Burger e Borja (2017), Souza (2016), Silva e Beato (2013), Brown e Benedict (2002), Cao, Stack e Sun (1998), entre outros. Por outro lado, nem todas as pesquisas de imagem identificadas neste estudo fazem uso da etapa qualitativa sugerida por Schuler e Toni (2015), optando por transformar a natureza qualitativa da variável imagem em uma passível de mensuração, como nível de confiança (Silva e Beato, 2013), de satisfação (Brown e Benedict, 2002; Mello, Toigo e França, 2004; Zouain, Cruz e Ross, 2008) ou ambos (Cao, Stack e Sun, 1998; Santos Júnior e Guerini, 2007). Outra possibilidade foi a utilização de pergunta fechada sobre a percepção da imagem, mediante escala variando de "muito fraca" a "muito forte" (Peak e Glensor, 1992).

No campo empírico, o relatório de pesquisa de imagem desenvolvido para o Tribunal de Contas de Goiás também revela a inexistência da fase qualitativa e os dados indicam ser a imagem mensurada pelo nível de satisfação e percepção de eficiência do órgão entre o público pesquisado (TCE/GO, 2010).

Como se observa, não há um consenso metodológico em relação à aplicação da pesquisa de imagem em organizações do setor público, indicando ser este um espaço aberto para novas propostas, reflexões e debates.

\subsection{Pesquisas de Imagem sobre a Polícia}

A produção acadêmica sobre estudos de imagem aplicados à polícia não é recente, contempla diferentes enfoques e faz uso de abordagens distintas de pesquisa, embora a quantitativa ainda seja destaque, principalmente em estudos que envolvem a percepção da população. Em levantamento sobre a produção acadêmica nacional e internacional sobre "imagem corporativa aplicada à polícia" publicadas até dezembro de 2017 foram identificados 74 artigos, dos quais 30 foram selecionados para análise.

Com uso das palavras-chave "police" AND "image" no campo título, a busca resultou em 50 artigos na base Web of Science e 22 na Scopus, duas das principais referências no campo das Ciências Sociais Aplicadas. Optou-se por incluir a mesma pesquisa na base Spell, pela concentração de periódicos nacionais. Nesta, foram utilizados termos em português, mas como não foram identificados artigos utilizando a busca no campo "título", optou-se por utilizar "resumo". Nesses parâmetros, foram identificados dois artigos. A Figura 1 indica o número de artigos encontrados em cada base e as exclusões realizadas - primeiramente pela temática, depois por repetição. Os artigos excluídos pela temática indicam estudos aplicados às áreas médica, jurídica e cultural - esta envolvendo temas como história, artes e entretenimento.

\begin{tabular}{|l|c|c|c|c|c|}
\hline Base de Dados & $\begin{array}{c}\text { Total de Artigos } \\
\text { (sem exclusão) }\end{array}$ & $\begin{array}{c}\text { Artigos fora do } \\
\text { tema }\end{array}$ & $\begin{array}{c}\text { Artigos não } \\
\text { cient. }\end{array}$ & $\begin{array}{c}\text { Artigos } \\
\text { Repetidos }\end{array}$ & Artigos Selecionados \\
\hline WEB OF SCIENCE & 50 & 25 & 1 & 0 & 24 \\
\hline SCOPUS & 22 & 09 & 0 & 8 & 07 \\
\hline SPELL & 02 & 01 & 0 & 0 & 01 \\
\hline \multicolumn{7}{|r|}{} \\
\hline
\end{tabular}

Figura 1. Levantamento nas Bases de Dados

Fonte: Elaborado pelos autores com base nos dados (2018)

Foram selecionados para análise os artigos que tratam da imagem na perspectiva corporativa, segundo a abordagem apresentada na revisão de literatura deste estudo. 
Observou-se que os estudos selecionados trazem não apenas um levantamento da percepção da população sobre a imagem da polícia - embora estes representem o maior quantitativo (18), mas também analisam a temática no contexto das produções midiáticas, com ênfase no papel da imprensa como influenciadora na construção da imagem (03) - e no contexto interno (9), com enfoque na percepção do efetivo sobre a própria instituição (imagem interna) e/ou questões de gerenciamento da imagem.

Cabe destacar que, dos artigos selecionados para análise, apenas cinco apresentaram quantitativo de citações superior a dez. A figura 2 indica as obras mais citadas com respectivos autores e periódicos.

\begin{tabular}{|l|r|l|l|r|}
\hline Título & Ano & Autores & Revista & Citações/Base \\
\hline $\begin{array}{l}\text { The image of the police in black Atlanta } \\
\text { communities }\end{array}$ & 1990 & $\begin{array}{l}\text { Murty, K.S., Roebuck, J.B., } \\
\text { Smith, J.D }\end{array}$ & $\begin{array}{l}\text { Journal of Police Science } \\
\text { and Administration }\end{array}$ & 66/ Scopus \\
\hline $\begin{array}{l}\text { Police Schools Liaison and Young } \\
\begin{array}{l}\text { Peoples Image of the Police - An } \\
\text { Intervention Evaluation }\end{array}\end{array}$ & $\begin{array}{l}\text { Hopkins, N; Hewstone, } \\
\text { M; Hantzi, A }\end{array}$ & $\begin{array}{l}\text { British Journal of } \\
\text { Psychology }\end{array}$ & $24 /$ WOS \\
\hline $\begin{array}{l}\text { Police News - Constructing an Image of } \\
\text { Crime }\end{array}$ & 1992 & Fishman, M. & Urban Life & $23 /$ WOS \\
\hline $\begin{array}{l}\text { Jack and Jill Join Up at Sun Hill: Public } \\
\text { Images of Police Officers }\end{array}$ & 1992 & Walklate, S. & Policing \& Society & $12 /$ Scopus \\
\hline $\begin{array}{l}\text { Force to sell: policing the image and } \\
\text { manufacturing public confidence }\end{array}$ & 2013 & Lee, M.; McGovern, A. & Policing \& Society & $11 /$ WOS \\
\hline
\end{tabular}

Figura 2. Artigos Mais Citados

Fonte: Elaborado pelos autores com base nos dados (2018)

Evidencia-se, entre as obras indicadas, apenas uma mais recente, de 2013. Esta constitui-se como um estudo de caso comparativo de caráter qualitativo que explora como os diretores de mídia e relações públicas dentro das organizações policiais australianas concebem as conexões entre o trabalho de construção de imagem, confiança pública na organização, confiança no policiamento e legitimidade na instituição policial. Cumpre destacar que esta obra inclui em sua análise a percepção dos gestores sobre o uso das mídias digitais na construção da legitimidade do órgão, mediante o uso das ações de comunicação (Lee \& McGovern, 2013). Naturalmente, tais ferramentas não estão presentes nos artigos mais antigos.

No tocante aos aspectos metodológicos, percebe-se uma diversidade na coleta de dados entre os artigos selecionados para análise. Pesquisas com a de Bonner (2010) que aborda a percepção da imagem da população sobre os Carabineiros do Chile, utilizou a abordagem qualitativa, com entrevistas semiestruturadas, feitas com 40 sujeitos, permitindo discorrer de forma mais aprofundada sobre o tema abordado. Já Perednia (2016), utilizou abordagem quantitativa para pesquisar a imagem da polícia na Rússia, com escalas de 10 pontos. Em outra pesquisa feita Hong Kong, sobre a atuação da polícia durante o Hong Kong Occupy Moviment, foi utilizado o método de análise de conteúdo, partindo de pesquisas feitas nos três jornais de maior circulação do país (Chan, 2015), permitindo, a partir do que foi publicado na mídia, levantar a percepção da atuação da polícia nesse contexto. Num cenário brasileiro, o trabalho de Zoian, Cruz e Ross (2008) abordou a percepção da comunidade sobre a Polícia Militar do Rio de Janeiro. A pesquisa quantitativa analisou dados secundários obtidos pela aplicação de 2250 questionários com cidadãos de diferentes classes sociais, mediante pesquisa realizada em 2005. Diante do levantamento bibliográfico frente a pesquisas de imagem da polícia no mundo, percebe-se que o uso de abordagens quantitativas permite um lastro maior da amostra, enquanto que as abordagens qualitativas permitem um maior aprofundamento na análise das percepções dos sujeitos.

Nas pesquisas quantitativas, quando aplicadas com a população, verifica-se uma frequente discussão sobre as variáveis sociodemográficas que devem ser utilizadas para explicar a variação da imagem corporativa em relação à polícia. 0 artigo mais citado entre os encontrados neste levantamento (Murty, Roebuck \& Smith, 1990), dá ênfase à questão racial, fato observado pela escolha dos sujeitos 600 indivíduos negros, residentes em uma comunidade de Atlanta. As variáveis sociodemográficas escolhidas neste trabalho foram idade; sexo; estado civil, educacional, ocupacional e de emprego; experiência (indireta e direta) com a polícia; e residência. Em estudo realizado a partir da análise de mais de cem artigos sobre percepções e atitudes da população em relação à polícia, Brown e Benedict (2002) identificaram que idade, contato com a polícia, local de moradia (vizinhança) e raça são variáveis 
que normalmente afetam percepções e atitudes em relação à polícia, entretanto, há fatores moderadores que não são claramente compreendido, fato que implica em cautela ao se abordar o tema de uma perspectiva mais generalizada.

\section{Método}

A presente pesquisa caracteriza-se como estudo exploratório, de abordagem quantitativa, mediante aplicação de pesquisa survey de corte transversal. A aplicação ocorreu por meio de questionário aplicado pelo entrevistador, contendo perguntas, abertas e fechadas, a respeito da percepção da imagem corporativa sobre a PMSC.

Foi considerado universo infinito, com amostra composta por 367 pessoas, o que representa margem de erro de 5,12\% e intervalo de confiança de 95\% (Mattar, 2005). A amostragem foi do tipo não probabilística por tráfego e conveniência (Mattar, 2005), consistindo nos transeuntes na região central da capital catarinense, que aceitaram participar da pesquisa. A coleta de dados se deu de forma presencial, durante o mês de setembro de 2017.

0 instrumento foi construído utilizando, inicialmente, escala de familiaridade (Kotler \& Keller, 2012) para identificar o nível de conhecimento sobre a PMSC. Para aqueles que responderam estar familiarizados com a organização (conhecem pouco, conhecem ou conhecem muito) foi perguntado o que a PMSC faz e, na sequência, qual a primeira palavra ou imagem que vem na cabeça ao se falar em Polícia Militar. Importante destacar que o questionamento sobre a primeira imagem que vem à cabeça é indicado para pesquisas de imagem (Schuler \& Toni, 2015); entretanto, a pergunta sobre a atividade da organização, em formato aberto, foi proposta ao estudo em função do pressuposto de que os cidadãos tendem a confundir as organizações, face a existência de múltiplas instituições com área de atuação afins. Complementarmente, o estudo incluiu pergunta sobre a logomarca associada à PMSC, igualmente para verificar o nível de reconhecimento dos símbolos da instituição. Além disso, o instrumento abarcou questionamentos sobre a qualidade do atendimento recebido, entre aqueles que manifestaram ter vivenciado contato direto com a PMSC. No bloco demográfico, buscou-se identificar o gênero, idade, escolaridade, estado civil, renda e orientação política, variáveis comumente abordadas em estudos sobre a percepção da polícia (Brown \& Benedict, 2002; Cao, Stack, \& Sun, 1998)

Os dados coletados foram analisados e tabulados em planilhas Excel para a elaboração de tabelas de frequências e cruzamentos. Para verificar associação da imagem às variáveis demográficas e atitudinais aplicou-se o teste qui-quadrado com uso do software de pesquisa SPSS v. 23. Na etapa de análise, ressalta-se que as respostas às perguntas abertas foram codificadas em imagem neutra, positiva e negativa (Gibbs, 2009). 0 processo de análise partiu da questão "qual a primeira palavra que lhe vêm à cabeça quando se fala em PMSC". Respostas que apresentaram carga valorativa foram categorizadas como positivas ou negativas. As associações à atividade da PMSC (segurança, proteção, policiamento, etc.) ou a elementos institucionais (policial, farda, viatura, etc.) foram submetidas a análise combinada da questão "o que a PMSC faz", respostas com carga valorativas foram categorizadas como positiva ou negativa; respostas que remetiam à atividade da PMSC (policiamento ostensivo, prende bandido, combate ao crime, etc.) foram categorizadas como neutras.

0 processo de codificação descrito foi realizado em dupla, sendo, num primeiro momento, feito individualmente pelos pesquisadores. Posteriormente os dados foram confrontados para observar as diferenças na categorização e assim, definir as categorias mais adequadas a cada caso.

\section{Discussão dos Resultados}

\subsection{Perfil Demográfico}

Os dados referentes ao perfil demográfico dos entrevistados estão sintetizados na Tabela 1, como se observa. Optou-se por apresentar na tabela somente os dados mais significativos, com a finalidade de auxiliar na compreensão do perfil do respondente.

\subsection{Conhecimento da PMSC}

Perguntou-se aos respondentes se conheciam a Polícia Militar de Santa Catarina. 65,4\% (240) disseram conhecerem a instituição, 27,2\% (100) afirmaram que conhecem muito e 7,4\% (27) que conhecem pouco. Tanto nas categorias "conheço", como "conheço muito" houve uma predominância entre o público masculino (137, 57\% "conheço"; 22, 81\% "conheço muito", sugerindo uma influência 
do gênero no nível de conhecimento manifestado.

Tabela 1 - Perfil Demográfico

\begin{tabular}{|c|c|c|c|c|c|}
\hline Sexo & № & $\%$ & Escolaridade & № & $\%$ \\
\hline Homem & 209 & 56,9 & \multirow{5}{*}{$\begin{array}{l}\text { Ensino Fundamental } \\
\text { Ensino Médio } \\
\text { Ensino Superior } \\
\text { Pós-Graduação }\end{array}$} & \multirow{5}{*}{$\begin{array}{l}84 \\
135 \\
179 \\
33\end{array}$} & \multirow{5}{*}{$\begin{array}{l}17,5 \\
36,7 \\
48,7 \\
9\end{array}$} \\
\hline Mulher & 158 & 43,1 & & & \\
\hline & & & & & \\
\hline Faixa Etária & № & $\%$ & & & \\
\hline $18-29$ anos & 123 & 33,5 & & & \\
\hline $30-39$ anos & 76 & 20,7 & Faixa Salarial & № & $\%$ \\
\hline $50-59$ anos & 75 & 20,4 & \multirow{5}{*}{$\begin{array}{l}\text { Até } 1 \text { salário mínimo (SM) } \\
\text { De } 1,1 \text { a } 3 \text { SMs } \\
\text { De } 3,1 \text { a } 6 \text { SMs } \\
6,1 \text { SMs ou mais }\end{array}$} & \multirow{5}{*}{$\begin{array}{l}48 \\
163 \\
79 \\
38\end{array}$} & \multirow{5}{*}{$\begin{array}{l}13,1 \\
44,4 \\
21,5 \\
10,4\end{array}$} \\
\hline Estado Civil & № & $\%$ & & & \\
\hline Solteiro (a) & 163 & 44,4 & & & \\
\hline Casado (a) & 133 & 36,2 & & & \\
\hline Divorciado (a) & 41 & 11,2 & & & \\
\hline Ocupação & № & $\%$ & Orientação Política & № & $\%$ \\
\hline Funcionário setor privado & 126 & 34,3 & Direita/ Centro-Direita & 26 & 7,1 \\
\hline Servidores públicos & 61 & 16,6 & Centro & 13 & 3,5 \\
\hline Aposentados/pensionistas & 42 & 11,4 & Esquerda/Centro-Esquerda & 53 & 14,6 \\
\hline Estudantes & 35 & 9,5 & Sem orientação política & 232 & 63,2 \\
\hline Desempregados & 29 & 7,9 & Outro perfil & 43 & 11,7 \\
\hline Empresários & 17 & 4,6 & & & \\
\hline
\end{tabular}

Fonte: Dados primários (2017)

Adicionalmente, foram apresentadas aos participantes seis elementos simbólicos referentes às organizações públicas cuja área de atuação envolve segurança. Posteriormente foi questionado quais imagens se referiam-se à PMSC. A relação dos símbolos é apresentada na Figura 3.

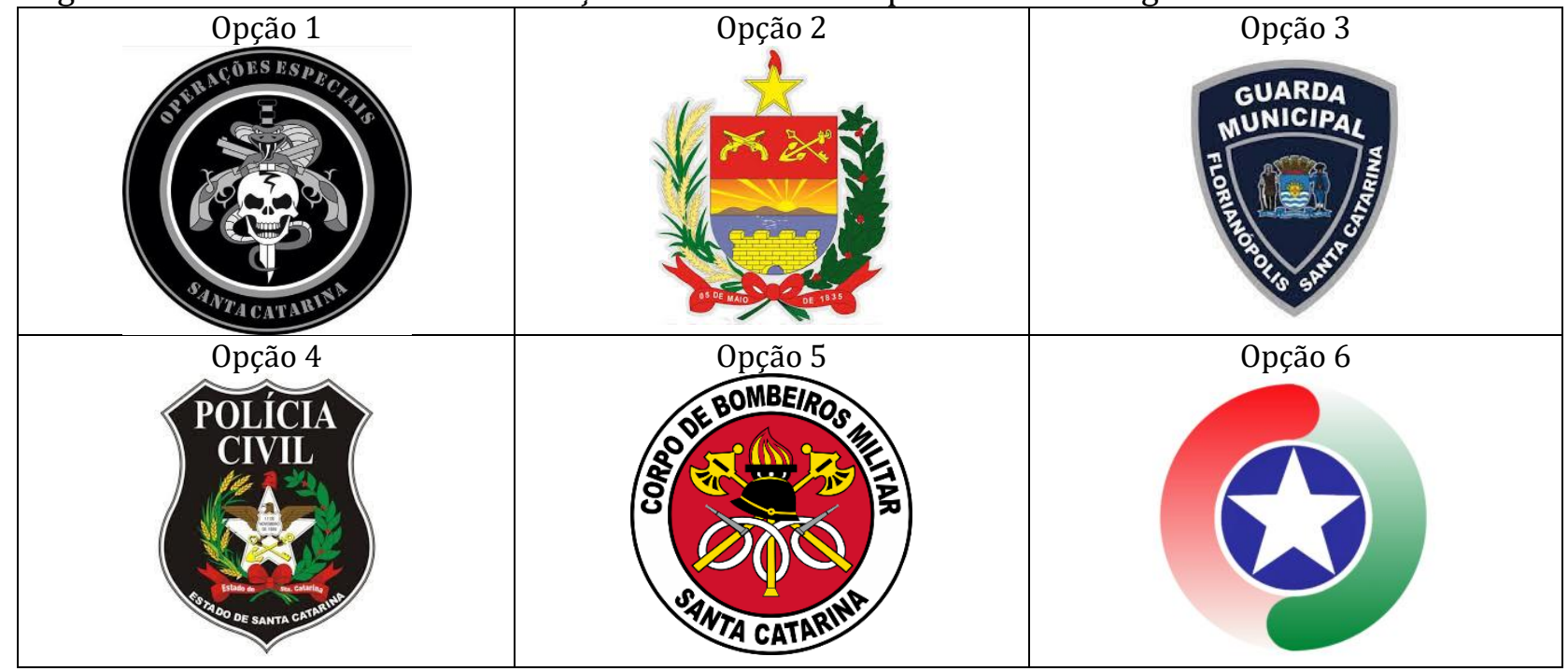

Figura 3. Relação de Símbolos

Fonte: As imagens foram obtidas nos websites institucionais dos órgãos públicos aos quais pertencem.

Das imagens apresentadas, somente as opções 1, 2 e 6 são da PMSC. 0 símbolo com a maior incidência de associação entre os respondentes à PMSC foi a opção 6 (87\%, 321). Em segundo lugar figura a opção $4(34 \%, 125)$ - Polícia Civil e, na sequência, a opção $3(22 \%, 80)$ - Guarda Municipal. Importante destacar que a logomarca faz parte da identidade e é considerada como um dos elementos que irão compor a imagem corporativa (Tran et al., 2015; Schuler \& Toni, 2015; Gray \& Balmer, 1998). Portanto, a associação de mais de $80 \%$ dos respondentes ao símbolo 6 sugere uma marca forte. Contrariamente, o brasão observado na opção 2 não apresenta a mesma força, uma vez que foi indicado por $10 \%$ (38) dos respondentes.

Interessante observar que a opção 6 apresenta menos elementos gráficos que a opção 2, corroborando ao argumento de que a logomarca deve ser simples para ser facilmente memorizável, “(...) deve-se evitar símbolos muito complicados, de difícil memorização ou interpretação (...). Há de se utilizar formas simples e familiares, mas que sejam, pelo estilo ou interpretação, inéditas, memoráveis, distintas, inconfundíveis." (Schuler \& Toni, 2015, p.108) 
Associações errôneas, como as observadas nas opções 3 e 4 também confirguram-se como um desafio gerencial, uma vez que eventuais experiências negativas com tais órgaõs podem resultar em avaliação negativa da PMSC, mesmo que a responsabilidade não seja desta. Naturalmente, a situação contrária também se aplicaria ao caso.

\subsection{Imagem da PMSC}

A análise da imagem foi feita a partir da pergunta sobre a primeira palavra ou imagem que surgia na mente do respondente ao se falar da Polícia Militar de Santa Catarina. Salienta-se nesta questão que a categorização entre respostas positivas, negativas e neutras foi elaborada a partir de uma análise conjunta das perguntas "Na sua opinião, o que a PMSC faz? " e "Quando se fala em 'Polícia Militar' qual a primeira palavra ou imagem que lhe vem à cabeça? ". No procedimento de categorização, buscou-se observar primeiramente se a resposta a primeira e/ou segunda questão aberta indicavam conotação positiva ou negativa. Entende-se aqui por conotação positiva menções que qualificam a PMSC positivamente, a exemplo "fazem um bom trabalho; corajosos; eficientes" e por conotação negativa as menções de natureza crítica, a exemplo "Não faz; pessoas violentas, corrupção". As associações que não assumiram conotação valorativa por serem vinculadas à própria natureza da PMSC foram classificadas como neutras, a exemplo: segurança, policial fardado, mantém a segurança. A Tabela 2 apresenta as principais associações observadas em cada uma das categorias e a Figura 2, na sequência, apresenta a nuvem de palavras realizada com os termos associados à imagem da PMSC.

Tabela 2 - Principais Termos Associados às Categorias de Imagem

\begin{tabular}{|c|c|c|}
\hline Imagem + (o que a PMSC faz) & № & $\%$ \\
\hline Imagem Neutra & 256 & 69,75 \\
\hline Segurança/ Segurança Pública + (cuidam da segurança; gera ordem; prende bandido) & 89 & 34,8 \\
\hline $\begin{array}{l}\text { Policial/ Policial fardado/ Pessoas fardadas/ Policial militar + (tenta proteger; garante a segurança; } \\
\text { mantém a ordem; proteção dos cidaãas; policiamento) }\end{array}$ & 42 & 16,4 \\
\hline Proteção + (protege o povo; mantém a ordem e segurança; repressão ao crime; garante a segurança) & 33 & 12,9 \\
\hline Outros ( $\mathrm{n}$ o de associações igual ou inferior a dez) & 81 & 31,6 \\
\hline Imagem Negativa & 63 & 17,16 \\
\hline Deveria ser (...segurança; fazer a segurança; proteger a população, "mas não faz") & 9 & 14,3 \\
\hline Agressividade/Violência (pessoas violentas, mal-encarados, reprimem manifestações) & 7 & 11,1 \\
\hline Corrupção + (fazem nada; falam mais do que fazem) & 6 & 9,5 \\
\hline Outros ( $\mathrm{n}$ - de associações igual ou inferior a cinco) & 41 & 65,0 \\
\hline Imagem Positiva & 48 & 13,07 \\
\hline Segurança/Segurança, pessoas corajosas + (tentam fazer o melhor; fazem um bom trabalho) & 8 & 17 \\
\hline Coragem/Corajosos/ Excelentes profissionais + (segurança; cumprimento da lei; proteção) & 7 & 15 \\
\hline Qualidade/Competência & 6 & 13 \\
\hline Outros (no de associações igual ou inferior a quatro) & 26 & 54,1 \\
\hline
\end{tabular}

Fonte: Dados primários (2017)

Houve uma significativa predominância de imagem "neutra" (69,75\%; 256). Similar ao observado em Souza (2016), estes respondentes realizaram associações à atividade ou símbolos da PMSC, sem atribuir juiízo de valor. 0 termo mais recorrente na questão referente à imagem foi "segurança", respondendo por 35\% (89) das associações realizadas no grupo de neutros. Entre as respostas sobre o que a PMSC faz, quando combinadas à imagem "segurança", estão: "cuidam da segurança pública", "gera ordem", "prende bandido", "garante a segurança e mantém a ordem", "protege e defende”, entre outras de natureza similar.

Outro termo recorrente no agrupamento de imagem neutra foi "policial" (16\%; 42), contemplando termos associados como "policial militar", "policial fardado", "pessoas fardadas", "soldado". Por fim, destaca-se "proteção" (13\%; 33) como imagem frequentemente associada à PMSC. A análise combinada do termo "proteção" ao que a PMSC faz identificou respostas como: "protege o povo", "mantém a ordem e segurança", "repressão ao crime", "garante a segurança", entre outras de natureza similar, indicadas pelos respondentes como a atividade da PMSC.

No tocante à imagem negativa, observa-se baixa concentração de termos vinculados a uma mesma associação, uma vez que 65\% das respostas desta categoria tem agrupamento igual ou inferior a cinco. Entre os mais recorrentes estão a fala de que a polícia "deveria ser ou fazer algo, mas não faz" (14,3\%; 9). Esta resposta foi observada tanto na questão da imagem, como "deveria ser segurança", quanto na questão referente à atividade, a exemplo "deveria proteger, mas...". No agrupamento agressividade/violência $(11,1 \% ; 7)$ as imagens mentais que surgiram foram associadas à pessoas 
violentas, mal-encaradas e à atos de repressão. 0 terceiro agrupamento, corrupção $(9,5 \%$; 6$)$ trouxe o termo como imagem associada à polícia e a expressão "não faz nada" como atividade.

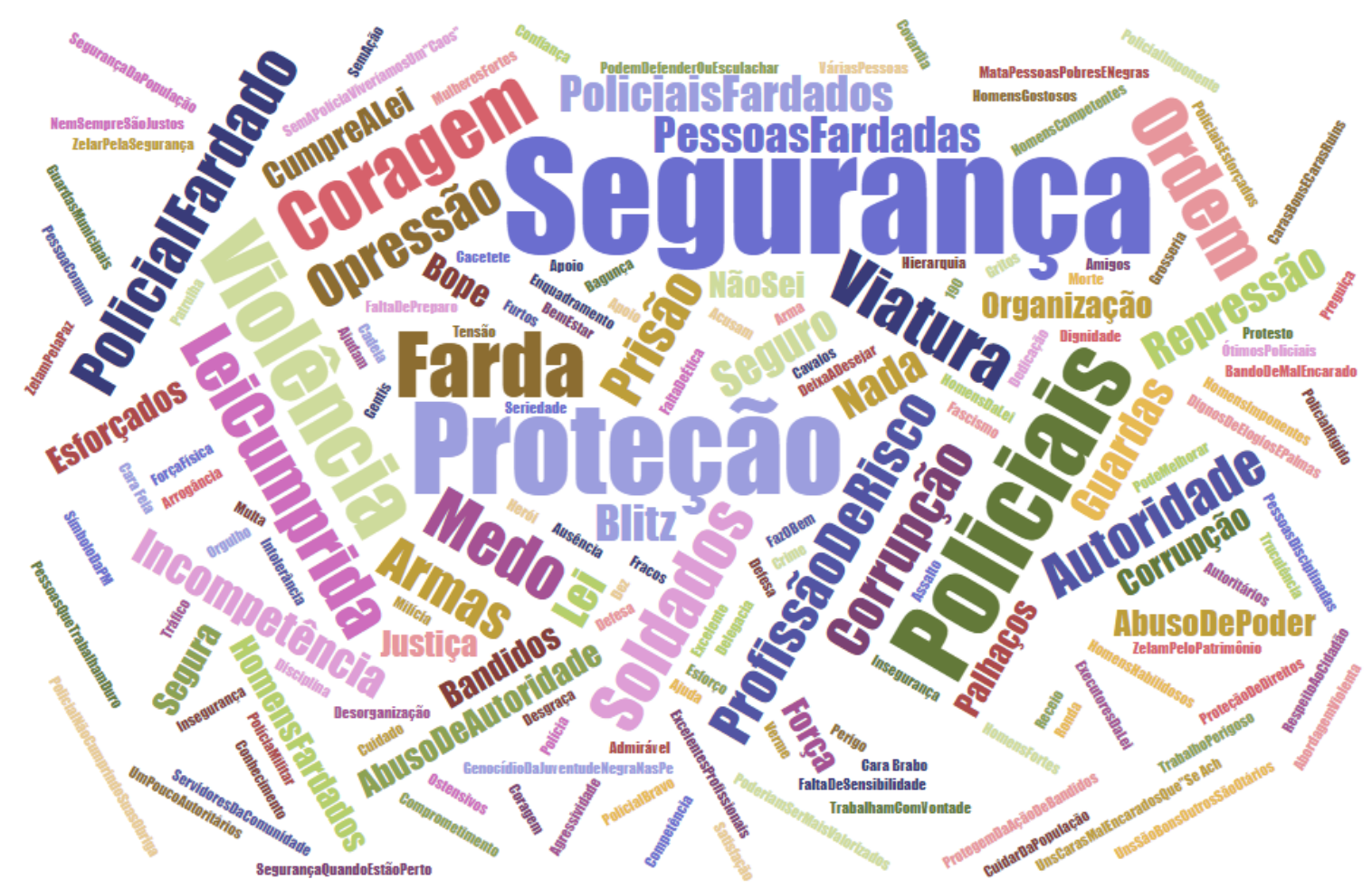

Figura 4. Nuvem de Palavras

Fonte: Dados primários (2017)

Nota. A nuvem de palavras foi criada com auxílio da ferramenta online e gratuita disponível no website "Word Cloud Generator - Jason Davis" https://www.jasondavies.com/wordcloud/

Em relação à imagem positiva, observou-se o mesmo fenômeno de baixa concentração de respostas em um agrupamento específico, sendo segurança $(17 \% ; 8)$, coragem $(15 \% ; 7)$ e qualidade $(13 \% ; 6)$ as principais associações. Interessante observar que o termo "segurança" também foi a principal referência no grupo de imagem neutra. Entretanto, figura como positivo em função das palavras que acompanham o termo - a exemplo, "me sinto segura, bem", "segurança e pessoas corajosas" - e das atribuições à PMSC, categorizadas como de caráter positivo, entre as quais: "tentam fazer o melhor" e "fazem um bom trabalho".

No agrupamento "coragem", as primeiras palavras associadas à PMSC já apresentaram conotação positiva, sem necessitar dupla verificação com a questão sobre a atividade do órgão. Os termos mais recorrentes neste grupo foram "pessoas corajosas", "pessoas que se arriscam/ arriscam a vida" ou simplesmente "corajosos". Por fim, o agrupamento "qualidade/competência" representa associações positivas como "excelentes", "satisfação", "10", "pessoas dignas de palmas e elogios", "competentes" e "profissionais". Os termos sugerem satisfação com a instituição PMSC, por este motivo, escolheu-se o rótulo indicado.

\subsection{Imagem X Variáveis}

Estudos de imagem comumente realizam cruzamentos da imagem percebida com variáveis demográficas e atitudinais (Souza, 2016; Cao, Stack, \& Sun, 1998; Skogan, 1996). Na presente pesquisa foi encontrada diferença estasticamente significativa (valor-p < ou igual a 0,05 ) entre as variáveis imagem e orientação política, quando aplicado o teste qui-quadrado. As demais variáveis apresentaram significância acima de 0,09, não permitindo apontar evidências de associação com a imagem.

0 teste qui-quadrado ao valor de 29,905 indicou significância assintótica a ,001 - apontando associação entre as variáveis. Como se observa na tabela cruzada, o comportamento do grupo "esquerda/centro-esquerda" e "outro" difere dos demais. Enquanto os grupos "centro", "direita/centrodireita" e "sem orientação" apresentam imagem negativa e positiva em percentuais semelhantes, os grupos "esquerda/centro-esquerda" e "outros" apresentam percentuais de imagem negativa superior 
ao de positiva - embora, em todos os grupos, a imagem que prevaleceu foi a neutra. 0 resultado confirma os achados de Cao, Stack, \& Sun (1998) e de Brown \& Benedict (2002), os quais sugerem que perfis políticos de esquerda apresentam menor confiança na polícia.

Tabela 3 - Imagem x Orientação Política

\begin{tabular}{|c|c|c|c|c|c|c|c|}
\hline & \multicolumn{5}{|c|}{ Orientação Política } & \multirow[b]{2}{*}{ Total } \\
\hline & & Centro & Dir./Cen.D. & Esq./Cen.Es. & Sem orient. & Outro & \\
\hline $\begin{array}{l}\text { Imagem } \\
\text { Negativa }\end{array}$ & $\begin{array}{l}\text { Contagem } \\
\% \text { em Pol. }\end{array}$ & $\begin{array}{c}2 \\
15,4 \%\end{array}$ & $\begin{array}{c}3 \\
12,0 \% \\
\end{array}$ & $\begin{array}{c}19 \\
35,8 \% \\
\end{array}$ & $\begin{array}{c}29 \\
12,4 \% \\
\end{array}$ & $\begin{array}{c}10 \\
23,3 \% \\
\end{array}$ & $\begin{array}{c}63 \\
17,2 \% \\
\end{array}$ \\
\hline $\begin{array}{l}\text { Imagem } \\
\text { Neutra }\end{array}$ & $\begin{array}{l}\text { Contagem } \\
\% \text { em Pol. }\end{array}$ & $\begin{array}{c}9 \\
69,2 \% \\
\end{array}$ & $\begin{array}{c}19 \\
76,0 \% \\
\end{array}$ & $\begin{array}{c}33 \\
62,3 \% \\
\end{array}$ & $\begin{array}{c}170 \\
73,0 \% \\
\end{array}$ & $\begin{array}{c}25 \\
58,1 \% \\
\end{array}$ & $\begin{array}{c}256 \\
69,8 \% \\
\end{array}$ \\
\hline $\begin{array}{l}\text { Imagem } \\
\text { Positiva }\end{array}$ & $\begin{array}{l}\text { Contagem } \\
\% \text { em Pol. }\end{array}$ & $\begin{array}{c}2 \\
15,4 \% \\
\end{array}$ & $\begin{array}{c}4 \\
12,0 \% \\
\end{array}$ & $\begin{array}{c}1 \\
1,9 \% \\
\end{array}$ & $\begin{array}{c}33 \\
14,2 \% \\
\end{array}$ & $\begin{array}{c}8 \\
18,6 \% \\
\end{array}$ & $\begin{array}{c}48 \\
13,1 \% \\
\end{array}$ \\
\hline Total & $\begin{array}{l}\text { Contagem } \\
\% \text { em Pol. }\end{array}$ & $\begin{array}{c}13 \\
100,0 \% \\
\end{array}$ & $\begin{array}{c}25 \\
100,0 \% \\
\end{array}$ & $\begin{array}{c}53 \\
100,0 \% \\
\end{array}$ & $\begin{array}{c}232 \\
100,0 \% \\
\end{array}$ & $\begin{array}{c}43 \\
100,0 \% \\
\end{array}$ & $\begin{array}{c}367 \\
100,0 \% \\
\end{array}$ \\
\hline
\end{tabular}

Fonte: Dados primários (2017)

\subsection{Imagem X Contato}

Na literatura sobre imagem é recorrente a afirmação de que a interação com o objeto, por meio de experiências, é importante elemento que influencia não somente os tipos, mas também a força da associação e, por consequência, a imagem (Boulding, 2007; Schuler \& Toni, 2015; Tran et al., 2015). Assim, buscou-se identificar, entre os pesquisados que já vivenciaram contato direto com a polícia militar, a avaliação do atendimento obtido para, posteriormente, relacioná-la à imagem percebida. Nesta pesquisa, do total de participantes, 71,1\% (261) afirmaram já ter tido contato com a PMSC. Para estes, solicitou-se a atribuição de uma nota de um a 10 para avaliar o atendimento da PMSC, sendo um=péssimo e 10=excelente. A média das notas foi de 6,98, com desvio padrão de 2,94 - indicando ampla variação das respostas.

Tabela 4 - Imagem X Contato

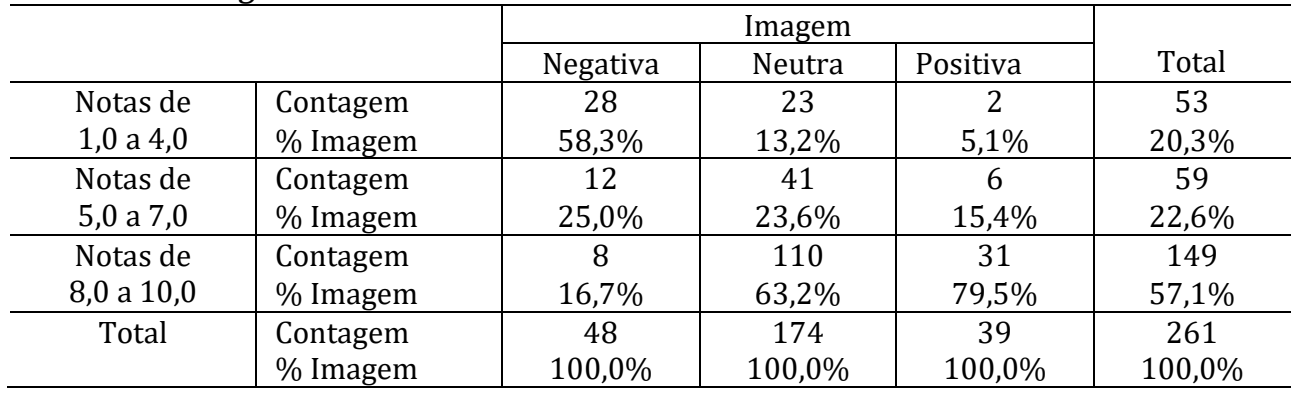

Fonte: Dados primários (2017)

O qui-quadrado aplicado com as variáveis "nota avaliativa do contato" e "imagem" indicou a existência de associações entre as variáveis, ao valor de 62,313 e significância assintótica de ,000. Observa-se, neste caso, que o grupo de notas mais baixas (de 1,0 a 4,0) apresenta maior concentração de imagem negativa, enquanto o grupo de notas mais altas (de 8,0 a 10,0), apresenta maior concentração de imagem positiva. 0 resultado corrobora os achados de Brown \& Benedict (2002), uma vez que confirma a relação entre contato e avaliação da polícia, no sentido de que, quanto mais positivo é percebida a interação, melhor a avaliação da polícia (e vice-versa). Entre as situações que favorecem uma avaliação positiva estão a forma de contato do policial com o cidadão e o fato do cidadão ter solicitado o contato - ao invéz de ser abordado por policiais (Brown \& Benedict, 2002). Se comparado com os achados de Silva e Beato (2013), observa-se certa divergência nos resultados, uma vez que os autores identificaram que "a maior parte dos contatos com a polícia, sejam eles compulsórios ou voluntários, provoca efeitos negativos no nível de confiança (...)" (Silva e Beato, 2013, 146). Ademais, apontam que a confiança é maior entre o público que mencionou não ter contato com a polícia.

\subsection{Implicações para a prática}

Estudos de imagem apresentam relevância à gestão de organizações públicas, especialmente àquelas que lidam diretamente com o cidadão. Considerando o contexto brasileiro, composto por instituições que atuam em esferas (municipal, estadual e federal) e poderes (executivo, legislativo e judiciário) distintos, como é possível afirmar que o cidadão saberá diferenciar cada uma das 
organizações? Pressupondo que o cidadão não tenha clareza das atribuições de cada órgão, como poderá dar legitimidade a uma instituição que não conhece plenamente? É neste cenário que as pesquisas de imagem em organizações públicas mostram-se relevantes. 0 presente estudo traz algumas reflexões, tendo como instituição objeto de análise a PMSC.

A primeira consideração a fazer diz respeito à gestão da marca. Organizações públicas são reconhecidas também por suas logomarcas. Numa situação em que coexistem tantos símbolos, uma logomarca que seja de fácil memorização minimiza os riscos de uma associação equivocada com outras organizações afins, bem como fortalece a imagem. É interessante observar que, no caso da PMSC, o brasão - um símbolo com elevada carga informacional - é pouco reconhecido como símbolo da instituição, ao passo que o escudo com a estrela é associado à PMSC por mais de $80 \%$ dos participantes da pesquisa.

0 segundo ponto a destacar diz respeito à imagem neutra. Avaliação do serviço e imagem corporativa são elementos relacionados, embora distintos. Para organizações públicas, a correta associação com a atividade prestada pelo órgão indica que o cidadão reconhece as suas principais atribuições, evitando possíveis confusões. No caso da polícia, equívocos entre a atribuição da PMSC e da Polícia Civil não foram marcantes, embora as atribuições à PMSC tenham sido descritas de maneira bastante simplificada e sem contemplar todo o foco de atuação da organização. Assim, uma imagem neutra, que revele uma correta associação de símbolos e atividades da PMSC pode representar uma situação tão favorável quanto uma imagem positiva, caso esta revele baixo conhecimento da instituição.

A terceira consideração diz respeito à posição política ideológica e sua relação com a imagem institucional. É possível que, para alguns grupos, a imagem de determinada organização pública seja positiva ou negativa sem que essa percepção tenha relação direta com a identidade corporativa ou com as ações de comunicação promovidas pela organização. É o caso da posição ideológica, construída por elementos históricos sociais, aproximando-se do conceito de "representação social" de Moscovici (2015). Em tais situações reforça-se a relevância da comunicação e do contato como possibilidades de construir experiências de interação positivas, capazes de sobrepor uma posição ideológica.

0 que leva à quarta consideração: a importância do contato na formação da imagem. No caso da PMSC e demais instituições que prestam serviços associados à proteção da vida e à segurança, a forma como interagem com a população pode ser determinante na formação da imagem. Conforme observado nos dados coletados, há uma concentração de avaliações de contato de notas entre 8,0 a 10,0 no grupo cuja imagem percebida da polícia foi categorizada como positiva. Da mesma forma, as avaliações de contato com notas entre 1,0 e 4,0 apresentaram concentração de imagem negativa. Considerando que a avaliação do contato representa a nota atribuída pela interação direta com os policiais, evidencia-se a relação entre essas variáveis e a necessidade da qualificação nos processos de interação, mediante treinamentos e capacitações.

Neste sentido, os resultados da pesquisa podem influenciar estratégias organizacionais especialmente no tocante à comunicação. Em uma primeira instância, a comunicação pessoal que ocorre mediante a interação de policiais e cidadãos, que pode ser orientada em sessão de treinamento e capacitação, por exemplo. Em segunda instância, a própria comunicação institucional, mediante a utilização da logomarca de maior associação e uso dos termos mais lembrados (segurança, proteção, imagem do policial fardado) combinados à elementos positivos, como os relacionados à coragem, competência e profissionalismo.

\subsection{Implicações para a teoria}

A imagem é tema complexo, de natureza multidisciplinar, podendo ser analisada sob diferentes perspectivas, desde a filosofia até o marketing, incluindo também a psicologia cognitiva e social (Schuler \& Toni, 2015). Em que pese os estudos já existentes sobre imagem aplicados ao setor público, o presente artigo adiciona alguns elementos no sentido de corroborar com a construção de uma agenda de estudos sobre a imagem corporativa em organizações públicas.

A começar pelo conceito de imagem, como visto a partir dos resultados do estudo, sugere envolver não apenas associações de carga valorativa, como também elementos simbólicos e, portanto, neutros. Assim, assume tanto características de reputação, quanto de uma imagem mental holística da organização (Christensen \& Askegaard, 2001; Gray \& Balmer, 1998).

Outro ponto que merece destaque diz respeito a possíveis elementos formadores da imagem em organizações públicas, controláveis e não controláveis pela organização. Neste estudo, observa-se o 
contato pessoal como elemento controlável, uma vez que diz respeito à comunicação pessoal dos membros da organização com o público externo. Tal situação confirma o modelo operacional de Gray \& Balmer (1998), em particular a afirmação de que a comunicação -entre elas, a pessoal - cria a imagem e reputação corporativa. Entre os elementos não-controláveis observa-se a posição política ideológica, presente neste estudo, e também em outras pesquisas envolvendo organizações policiais (Brown \& Benedict, 2002).

\section{Conclusões}

Criar uma imagem sobre qualquer coisa é um comportamento natural do ser humano. A partir do momento que se conhece algo, desenvolve-se uma imagem deste "algo", que pode ser uma pessoa - ou outro ser vivo - um objeto, uma ideia ou uma organização. 0 estudo das imagens busca compreender como elas se formam, os motivos que a fazem permanecer na memória e seus impactos no comportamento (Schuler \& Toni, 2015).

Esta pesquisa buscou analisar a temática sob a perspectiva de uma organização pública presente no cotidiano da população: a polícia militar. Entende-se aqui tratar-se de organização do cotidiano porque, mesmo que o cidadão não tenha contato direto com a polícia, é frequente a menção em jornais televisivos, impressos, online e nas redes sociais. Assim, é difícil imaginar que alguém nunca tenha ouvido falar da PM.

O presente estudo também buscou mostrar aplicação e a importância da pesquisa de imagem em uma organização pública. Embora pesquisas de imagem no âmbito público muitas vezes sejam confundidas com a imagem política dos governos (Kanaane et al., 2010), tais ferramentas visam mapear as associações que um público faz a uma determinada organização, explorando relações com variáveis e percepções distintas em função de determinadas características do público. Em adição, poucas são as pesquisas de imagem realizadas nas instituições públicas brasileiras, demonstrando uma área a ser explorada.

Importante ressaltar que a temática da imagem corporativa aplicada em organizações públicas pode ser explorada de variadas formas. Considerando o foco de estudo, a PMSC, sugere-se a realização de uma pesquisa de imagem interna, para observar as associações existentes entre os próprios policiais, possibilitando um comparativo à posteriori entre a imagem interna x externa da organização. Este mesmo comparativo pode ser aplicado a outras organizações públicas.

Novamente no tocante à realidade catarinense, um estudo mais amplo, contemplando todas as regiões do Estado, permitiria a análise da imagem em função do tamanho do município, em iniciativa similar a Silva \& Beato (2013).

A pesquisa de imagem, como abordado neste estudo, traz como principal contribuição reflexões acerca das metodologias que envolvem a aplicação deste tipo de pesquisa em organizações policiais. A proposição feita neste estudo reside na inclusão de questões abertas ao instrumento de coleta, que busquem identificar as associações feitas à Polícia Militar quando o respondente escuta o nome da organização, bem como as associações feitas às atividades da polícia. A categorização proposta, em imagem positiva, negativa e neutra inclui esta última como possibilidade de associação, uma vez que os demais estudos apresentam categorizações polarizadas. Entende-se que tal movimento pode auxiliar o campo de estudos sobre as Polícias Militares, como também os estudos de imagem aplicados ao setor público.

Ademais, cabe destacar que o estudo traz informações relevantes para o desenvolvimento de estratégicas de comunicação corporativa, sejam elas pessoais ou impessoais. Entre os principais resultados, o estudo mostrou a força de uma logomarca com poucos elementos, facilitando a memorização. Esta informação pode suscitar estratégias de comunicação da PMSC que reforcem o uso da logomarca do escudo com a estrela e evitem o uso do brasão - utilizando-a para situações mais formais, por exemplo.

Outro resultado que impacta em estratégias de comunicação diz respeito à relação entre o contato e a imagem, uma vez que, em todo contato pessoal e direto ocorre uma comunicação pessoal. Neste sentido, treinamentos orientando os membros a como interagir com a população, de forma a dar força às associações "segurança", "proteção", "qualidade/competência" podem auxiliar a organização no processo de fortificação de uma imagem positiva perante a população catarinense.

Considerando-se o fato de que a amostragem utilizada se configura como não probabilística, não é possível afirmar que o perfil dos respondentes corresponda inteiramente com o perfil populacional 
dos moradores da Grande Florianópolis.

\section{Referências}

Abratt, R. (1989). A New Approach to the Corporate Image Management Process. Journal of Marketing Management, 5(1), pp. 63-76.

Bonner, M. D. (Nov. de 2013). The Politics of Police Image in Chile. Journal of Latin America Studies, 45, pp. 669-694.

Boulding, K. E. (2007). The Image: Knowledge in Life and Society (5aㅡ ed.). Michigang: University of Michigang Press.

Brown, B., \& Benedict, W. R. (2002). Perceptions of the police: Past findings, methodological issues, conceptual issues and policy implications. Policing: An International Journal of Police Strategies \& Management, 25(3), pp. 543-580.

Cao, L., Stack, S., \& Sun, Y. (1998). Public Attitudes Toward the Police: A Comparative Study Between Japan and America. Journal of Criminal Justice, 26(4), pp. 279-289.

Chan, W. (July-September de 2015). The Media Representations of Police Image: Research Notes on the Hong Kong's Occupy Movement. SAGE Open, pp. 1-7.

Christensen, L. T., \& Askegaard, S. (2001). Corporate identity and corporate image revisited - a semiotic perspective. European Journal of Marketing, 35(3/4), pp. 292-315.

Chun, R. (2005). Corporate reputation: Meaning and measurement. International Journal of Management Reviews, 7(2), pp. 91-109.

Dowling, G. R. (1986). Managing Your Corporate Images. Industrial Marketing Management, 15, pp. 109-115.

Duarte, J. (2007). Comunicação Pública: Estado, Mercado, Sociedade e Interesse Público. . São Paulo: Editora Atlas.

Fishman, M. (1981). Police News - Constructing an Image of Crime. Urban Life, 4(9), pp. 371-394.

Gibbs, G. (2009). Análise de Dados Qualitativos: coleção pesquisa qualitativa. Porto Alegre: Artmed. Gray, E. R., \& Balmer, J. M. (1998). Managing Corporate Image and Corporate Reputation. Long Range Planning, 31(5), pp. 695-702.

Grunig, J. E. (1993). Image and Substance: from Symbolic to Behavioral Relationships. Public Relations Review, 12(2), pp. 121-139.

Hopkins, N., Hewstone, M., \& Hantzi, A. (May de 1992). Police Schools Liaison and Young Peoples Image of the Police - An Intervention Evaluation. British Journal of Psychology, 83, pp. 203-220.

IBOPE. (2016). Confiança da população nos brasileiros em geral é a menor desde 2009. Acesso em 08 de 01 de 2018, disponível em IBOPE Inteligência: http://177.47.5.246/noticias-e-pesquisas/confiancada-populacao-nos-brasileiros-em-geral-e-a-menor-desde-2009/

Kanaane, R., Filho, A. F., \& Ferreira, M. G. (2010). Gestão Pública: planejamento, processos sistemas de informação e pessoas. São Paulo: Editora Atlas.

Kennedy, S. H. (1977). Nurturing corporate images. Total communication or ego trip? European Journal of Marketing, 11(1), pp. 120-164.

Kotler, P., \& Keller, K. L. (2012). Administração de marketing (14ª ed.). São Paulo: Pearson Education do Brasil.

Kunsch, M. (2003). Planejamento de Relações Públicas na Comunicação Integrada. São Paulo: Summus Editorial.

Lee, M., \& Mcgovern, A. (Jun. de 2013). Force to sell: policing the image and manufacturing public confidence. Policing \& Society, 23(2), pp. 103-124.

Martineau, P. (Nov-Dez de 1958). Sharper focus for the corporate image. Harvard Business Review, 6 , pp. 49-58.

Mattar, F. N. (2005). Pesquisa de marketing: metodologia, planejamento. (6. ed. rev., atual. e ampl. ed.). São Paulo: Atlas.

Moscovici, S. (2015). Representações sociais: investigações em psicologia social (11ª ed.). Petrópolis, RJ: Vozes.

Murty, K. R. (Dec. de 1990). The image of the police in black Atlanta communities. Journal of Police Science and Administration, 17(4), pp. 250-257.

Perednia, D. (2016). Self-image and the perceived image of police in Russia. Sociological Studies, 1, pp. 152-157. 
PMSC. (2018). Brasão e Logomarca da PMSC. Acesso em 15 de 02 de 2018, disponível em Polícia Militar de Santa Catarina: http://www.pm.sc.gov.br/institucional/valores/

Rindell, A. (2013). Time in corporate images: introducing image heritage and image-in-use. Qualitative Market Research: An International Journal, 2, pp. 197-213.

Santos, A. R., Costa, J. I., Burger, F., \& Borja, G. R. (2017). Quem conhece as ouvidorias públicas? um estudo sobre a imagem percebida por cidadãos de Florianópolis (SC). Cadernos Gestão Pública e Cidadania, 22(73), pp. 400-421.

Schuler, M., \& Toni, D. d. (2015). Gestão da imagem de organizações, marcas e produtos através do MCI: Método para Configuração de Imagem. São Paulo: Atlas.

Silva, G. F., \& Beato, C. (2013). Confiança na polícia em Minas Gerais: o efeito da percepção de eficiência e do contato individual. OPINIÃO PÚBLICA, 19(1), pp. 118-153.

Skogan, W. G. (1996). The Police and Public Opinion in Britain. American Behavioral Scientist, 39(4), pp. 421-432.

Souza, S. A. (2016). 0 que é um Tribunal de Contas? Estudo sob a Perspectiva Popular, em Curitiba (PR). Cadernos Gestão Pública e Cidadania, 21(70), pp. 282-302.

Tran, M. A., Nguyen, B., Melewar, T., \& Bodoh, J. (2015). Exploring the corporate image formation. Qualitative Market Research: An International Journal, 18(1), pp. 86-114.

Walklate, S. (April de 1992). Jack and jill join up at sun hill; public images of police officers. Policing and Society, 2, pp. 219-232. 